\title{
I. M. Gelfand and His Seminar-A Presence
}

A. Beilinson

How nice to be like a fool for then one's Way is grand beyond measure

From a poem of Tainin Kokusen given to his student Ryõkan Taigu, 1790

The mathematical seminar of Israel Moiseevich Gelfand started each year in the beginning of September and ended in the spring when IM would observe that "rivulets (of melting snow) are beginning to flow." The sessions were on Mondays in the big auditorium on the 14th floor of Moscow University's main building, and each consisted of two parts: a preseminar that began at $6 \mathrm{pm}$, and the seminar proper, which began with IM's arrival at around $7 \mathrm{pm}$ and ended at $10 \mathrm{pm}$ when a cleaning lady entered the room to announce her departure (at which time the floor was to be locked, and those wishing to spend the night at home had to hurry down). During the preseminar dozens of people congregated near the auditorium entrance, chatting and exchanging books and texts of all kinds. ${ }^{1}$ The seminar typically began with IM telling some anecdotes and mathematical news, after which would come a talk by an invited speaker. ${ }^{2}$ Often there was not enough time to finish, and the talk continued serially, each time beginning from scratch and covering about half of the material from the week before, the speaker gradually fading away and being replaced by a student assigned by IM to explain what the talk was, or should have been, about. Any speaker deemed not to have understood the subject, or to have explained it badly (or if the writing was too small and the voice not clear) was harshly reprimanded. ${ }^{3}$

The seminar started in 1943; I saw its later years, which coincided with the late period of the Soviet Union. After Stalin's death the edifice of the state shrank into itself, and free space teemed with life. The ideology had lost its fulcrum, the show of democracy was simple (a single candidate to vote for, not two equally unpalatable ones), newspapers were mostly used as toilet tissue. The remaining taboos were private commerce ${ }^{4}$ and entrepreneurship, and political activity outside the Party's

A. Beilinson is the David and Mary Winton Green University Professor at the University of Chicago. His email address is sasha@ math.uchicago.edu.

For permission to reprint this article, please contact:

reprint-permission@ams.org.

DOI: http://dx.doi.org/10.1090/noti1337

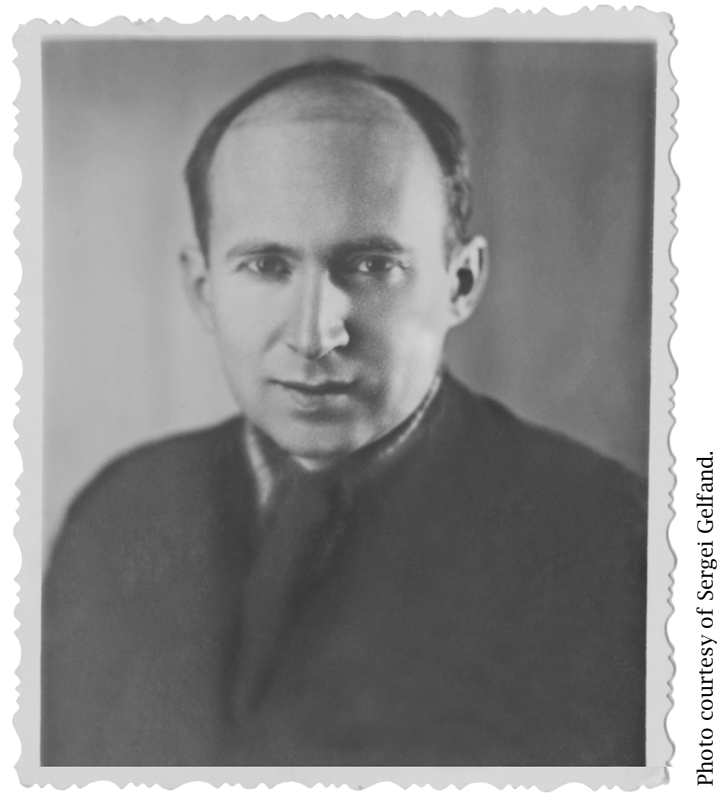

Undated photo of I. M. Gelfand, probably from the 1940s.

womb. Many people shared the attitude of Pushkin's poem "From Pindemonte" ${ }^{5}$ and viewed all matters political as not interesting anyway. The market in a modern sense, this incessant gavage of unneeded things, did not exist. One could quit the tarmac road to look for one's own trail into the woods. If the trail happened to be mathematics, it would surely meet with IM's seminar.

There was a distinct inner music. ${ }^{6}$ The air was thin and transparent. One could hear the sound of one's breathing, of snowflakes falling, of hoarfrost's brush decorating the windowpane. Old villages still existed within Moscow limits, such as wonderful Dyakovo, its empty church over an ancient cemetery on a high scarp above Moscow River, wooden houses edged by deep ravines, and vast apple gardens where nightingales sang. ${ }^{7}$ Poetry was by far more real than social ranks-poems were rewritten by hand and learned by heart. ${ }^{8}$

I was brought to the seminar and introduced to IM by Alesha Parshin in the fall of 1972; I was then a senior of the second mathematical school (IM taught there years earlier). The precious feeling of being a fool and despite that, or rather thanks to that, being in balance with life's 


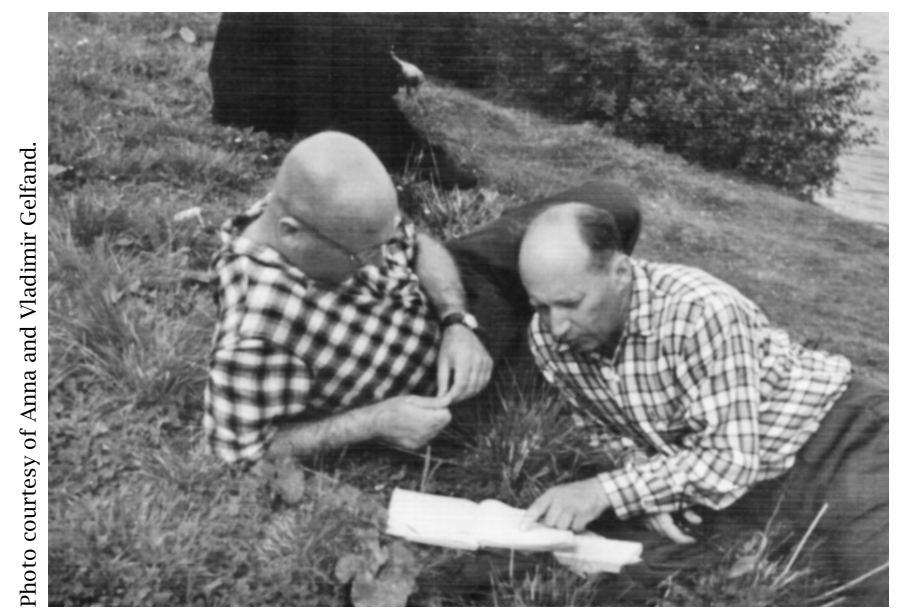

Mark Iosifovich Graev (left) and I. M. Gelfand on Volga River in summer 1963.

flow, akin to running on the cracking ice of a river, goes back to these days.

After failing the entrance exams to the math department of Moscow University ${ }^{9}$ I found myself in the lovely Pedagogical Institute. This was a benison-going to classes or playing truant in the morning, going to mathematical seminars or taking a train to walk in the woods ${ }^{10}$ later in the day; and there were wonderful friends. After a while I managed to be transferred to the University. The mood there was more sombre, but with no desire for higher grades, one could skip all the ideological classes ${ }^{11}$ to retain the good measure of idleness and freedom that are so necessary for doing math.

Accidentally, my first result to be published was close to the one found at the same time (the end of 1977) by IM with Osya Bernstein and Serezha Gelfand. IM gave a talk about his work, mentioning that I had obtained a similar theorem. After the talk I approached IM, and he at once ordered me to leave Yuri Ivanovich Manin, who was my supervisor, and be his student. The colée was violent. I refused. When I told YuI about the accolade, he said this had happened to many, e.g., to himself and to Shafarevich. Thereafter I stayed in an outer orbit of IM's influence, and our relationship was excellent.

After the graduation I got a job in a mathematical laboratory at Moscow Cardiological Center; to that end, the noble Vladimir Mikhailovich Alexeev, who was the head of the laboratory, came to the job committee soon after undergoing major cancer surgery. VM died in December of 1980. The new head of the lab, disagreeable on the matter of skiving, was keen on getting rid of me. After IM learned about the situation, he talked to the head of biological sector of the Center; I was transferred there and left to my own devices. The sinecure was better than a graduate school.

In the early 1970s the high winds of the Cold War' ${ }^{12}$ brought permission for Soviet Jews to emigrate, and many signed up for what, in retrospect, turned to be a verification of the universality of Griboyedov's quip that the place where it is better for us to be is where we are not. ${ }^{13}$ The separation from friends was deemed to be permanent (the imminent demise of the SU was anticipated then no more than that of the US is now). Dima Kazhdan, Ilya Iosifovich Piatetski-Shapiro, and Osya Bernstein, with whom we were happily doing math for his last half year in Moscow, were among those who left. No one at the seminar could replace them.

IM loved playing with people (with him mischief was never far away). ${ }^{14}$ A common way to engage someone was to explore his feeling of self-importance. IM rarely lost the game; if this happened (which meant that the opponent was more unpredictable than IM himself), he was furious, but the winner got his respect and, perchance, even love. For example, IM could ask you to wait and then disappear for a very long time. ${ }^{15} \mathrm{~A}$ cheap win was to leave after an hour. A master stroke would be different. According to legend, when IM returned to his office after several hours to see how Misha Tsetlin was doing, he found Misha fast asleep on the sofa. ${ }^{16}$

IM appreciated life. ${ }^{17}$ Although IM was a very social person, he paid no outward respect to problems caused by a lack of inner happiness (as a result he was often perceived as rude). ${ }^{18}$ He did what interested him for its own sake, and not as a part of any grand project. ${ }^{19}$ Running seminars (the mathematical and biological ${ }^{20,21}$ ones, and, starting from 1986, the one on informatics) was always interesting.

[IM] did what
interested him for
its own sake, not
as part of any
grand project.

Then there was the work with physicians, a long attempt to find out how a doctor diagnoses heart disease. While the attempt itself ended in failure, ${ }^{22}$ it included several top notch physicians who brought a distinctly new dimension to the

life of those around IM. I came then to know three doctors, true masters, who found it impossible to accept any payment for their help. ${ }^{23}$ I learned that such an attitude is utterly natural and, in truth, a doctor cannot behave any differently. ${ }^{24}$

IM emphasized the importance of decency. ${ }^{25}$ Its two realizations central, in my opinion, to IM's life were severing, after the work on the bomb, his ties with the military (late 1950s) ${ }^{26}$ and his becoming a vegan (mid 1990s). ${ }^{27}$ Both have to do with overcoming the habit of what is usually called thinking objectively, i.e., paying no regard to violence directed towards others. ${ }^{28}$ Arguably, without the first decision the world around IM would have been much less colorful and the seminar quite different. Becoming vegetarian is probably no less essential. It may loosen knots tied hard in one's mind, bringing back an ability to see many things as obvious and simple.

One difference between IM's seminar and other great mathematical seminars was its openness: the talks were not aimed at explaining any distinctive subject, nor were they connected to IM's current work, but rather these were stories that might contain a call from the future. This was in tune with the next feeling: We are used to 
seeing science's accomplishments as being fundamental. Over time the magical picture switches, and we realize that, in fact, we know almost nothing about the world, and science merely attempts to hide the vast openness. But we are able to wonder and take in new things, and I feel gratitude, only due to the wind that blows through us.

IM often said that he does not consider himself to be clever. ${ }^{29}$ A fool's way to see things differs from that of a clever person like peripheral vision differs from central vision. At every moment there are infinitely many possible directions to look at and to choose. A fool retains awareness of that; a clever person moves successfully in one or two directions while forgetting completely the remaining infinity of dimensions. A new understanding or a fresh poem starts with a tiny movement into an unknown dimension, which is the inimitable act of a fool.

Modern mathematics is a unique thrust of conceptual thought: once the right concept (a mathematical structure) and a language to deal with it are found, a whole new world unfolds. ${ }^{30}$ So for a mathematician it is very tempting to search for an adequate language as a key for understanding nonmathematical subjects, e.g., biology. This vision was dear to $\mathrm{IM}^{31}$ One reason why it has not been realized might be the following:

Science invariably considers reality as if from outside, the objects of study clearly distinct from the observer. But mathematical structures are part of the true reality that can be seen only from inside, the object of study being inseparable from the activity of our brain. It might be that adequate languages are peculiar to exactly this type of seeing. For example, except on the most superficial level, science is blank about the ways animals interact with the world. The animal's vision should be so wonderfully different to the human's that being privy to it might drastically change our understanding of what reality is. It is in such a quest that an adequate language could be ignited. Which is a mere foolish dream as long as we persist in positioning ourselves as separated from other living beings and above them-to the degree of imagining that the earth, the animals, and the trees can be our property. Incidentally, this same delusion underlies the drive for the destruction of the planet (which has accelerated so much since I saw IM the last time).

As I am writing these lines, it is spring, the season when the past does not seem to be that impossibly separated from the future. Great seminars have something of faerie horses in their nature. Bayard is said to be still living somewhere since his escape into the heart of the wild forest of Ardennes.

$$
* * * * * * * *
$$

This essay would not exist without many walks and discussions with Jesse Ball, Spencer Bloch, Irene(!) and Nicodemus Beilinson, Volodya Drinfeld, Dennis Gaitsgory, Anyuta and Volodya Gelfand, Senya Gindikin, Dima Kazhdan, Dima Leshchiner, Yuri Manin, Oleg Ogievetsky, and Eric Shutt, the request of Slava Gerovitch to write it down, and the interest and help of Allyn Jackson. My deep gratitude to them.

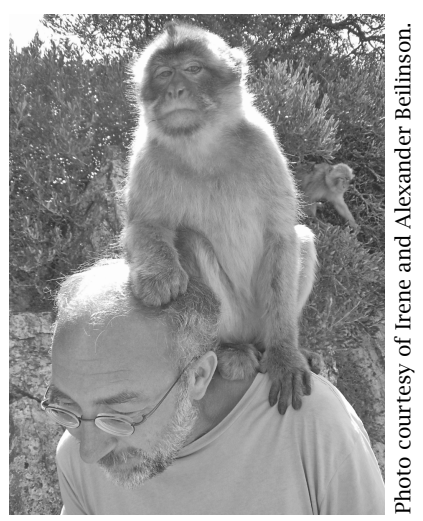

A. Beilinson.

\section{Notes}

${ }^{1}$ Senya Gindikin: "IM considered these preseminar discussions to be very important. However, he was pathologically disorganized and could not get anywhere on time even if he wished to (e.g., for a meeting with important people)." According to legend, once, on his way upstairs to a meeting with a President of the Academy of Sciences, IM stopped to exchange pleasantries with a cleaning lady; he never reached his destination.

${ }^{2}$ For Misha Shubin's notes of the talks, see www.mccme.ru/ gelfand/notes/.

${ }^{3}$ At times the scene resembled the koan about Nansen and the cat; see en.wikipedia.org/wiki/Nanquan_Puyuan with no Jõshũ in sight.

${ }^{4}$ One exception was Bird's Market in Moscow, where on the weekends all kinds of animals were sold. Once, when I visited it with Don Zagier, a bearded fellow in sheepskins tried to sell him a snow-white goose. The fellow said that he could see Don to be a true gentleman-otherwise he would not offer him the beauty. He said that she would be Don's best friend, going with him everywhere, and sharing his bath. The discussion was in French.

${ }^{5}$ For Nabokov's translation, see https://ireaddeadpeople. wordpress.com/2014/11/06/a1exander-pushkin-to-stro11in-ones-own-wake/.

${ }^{6}$ Perhaps not unlike that of another closed country-Japan of the late Edo era. The mores were also not altogether different: e.g., the chief nuclear scientist who dealt with Chernobyl's aftermath killed himself, probably, as an apology for his involvement in the nuclear industry (his superiors practiced the Fukushima era ethics).

${ }^{7}$ Dyakovo was eliminated in the 1980s: first the graves in the cemetery were dug out, then, in a while, the houses were demolished and burned, a single one surviving for over a year.

${ }^{8}$ Two of my friends knew by heart all of Mandelstam's poems. Cf. "An evening of Russian poetry" by Nabokov, www. sapov.ru/novoe/n00-39.htm.

${ }^{9}$ The lords of the Moscow mathematical establishment kept it clean from anything Jewish. 
${ }^{10}$ For a year I was seeing the woods almost every day.

${ }^{11}$ Officially one had to know the whole contents of the course in order to pass. But the teachers, with the help of the Komsomol leader of the group, revealed on the eve of the exams to each student the exact question he/she would be asked.

${ }^{12}$ Its sole cause was (is) the incompatibility of plutocracy and autocracy; the rest of the US/SU discordances were red herrings (or, if the reader prefers, forget-me-nots of a Kozma Proutkoff fable that was often cited by IM; see www. math. uchicago. edu/ mitya/langlands/nezabudki . html for an English translation).

${ }^{13}$ These departures, the simulations of dreams, had little in common with the high quest of crossing the SU border (in either direction) by one's own free will and with no external purpose, as in Nabokov's Glory or as done by Slava Kurilov, see his book Alone in the Ocean, rozamira.org/lib/names/k/kuri1ov_s/ kurilov.htm 1 (in Russian).

${ }^{14}$ Spencer Bloch: "I am sure I told you my Gelfand story when he came to Paris and was to meet with Serre. He was staying at Ormaille and the people at IHES needed someone to escort him to Paris. I was elected. I suggested we take a train with plenty of time to spare so we would not inconvenience the great Serre. Of course, I did not fully grasp the subtle thinking process of my charge. Suffice it to say that not inconveniencing Serre was rather low on the totem pole of Gelfand's priorities. I arrived at his apartment and he announced that he would instruct me on the Russian technique for making tea. So, of course, we missed the train. But I said no matter, there would be another train along in twenty minutes. But no, Gelfand said that errors had occurred during the making of the tea, and nothing would do except to return to his apartment and make more tea; which we did. So, of course, we missed the next train. And, as was clearly the intent from the beginning, the great Serre was made to wait for the great Gelfand."

${ }^{15}$ Senya Gindikin: "I would think that it was more complicated. IM felt no obligations and at every moment did only what he wished to do at that moment. I don't think he did anything intentionally, he could be distracted for a long while. I have a big personal experience here."

${ }^{16}$ Misha Tsetlin, who for IM was what, probably, Jõshũ was for Nansen, died in 1966. About their research in physiology, see sect. 3.1 of M. Latash's book Synergy, Oxford University Press, 2008, books.goog1e.ru/books?id=Z450j8yCQMIC\& pg=PA53. See also V. V. Ivanov's article about Tsetlin, historyofcomputing.tripod.com/essays/CETLINM. HTM

(in Russian).

${ }^{17}$ And, just maybe, he admired its beauty to the point where even ugly human deeds do not blot the clarity of vision. I believe that wild animals are not afraid of humans who are able to participate that much in the joy of being.

${ }^{18}$ On the other hand, IM did care a lot when the problem was real: e.g., his help was crucial for saving the lives of Sasha Zamolodchikov and the son of Tolya Kushnirenko after terrible accidents.

${ }^{19} \mathrm{IM}$ often said that he abandoned research whenever its subject became too popular.
${ }^{20}$ Volodya Gelfand: "IM knew no biology, but was always able to identify true experts to talk to, and these discussions were often very beneficial for the biologists as well."

${ }^{21}$ IM was fascinated by biology for the mystery that you do not know even how to think about is so immediate there.

${ }^{22}$ Perhaps at the start IM did not recognize medicine as an art (for him, a nonmathematician's project to uncover the way a mathematician proves theorems would be laughable). The work on a simpler problem of diagnosis of meningitis was successful.

${ }^{23}$ The payment for a cab to bring them, after the workday at hospital, to the patient's home included.

${ }^{24} \mathrm{~A}$ simple criterion to check if a given human society is not dead at its core is the presence in it of such physicians.

${ }^{25}$ Dima Leshchiner: "I recall his favorite saying: 'People do not have shortcomings, but only peculiarities.' It seems to me this has to do with what 'decency' meant in his understanding, namely, that 'decency' is the quality of an action, not of a person."

${ }^{26} \mathrm{IM}$ once told me that, back then, he was offered to be the head of any institution of his choice (say, Institute of Applied Mathematics that dealt with military projects) and he refused. Senya Gindikin: "I am not sure if anyone knows how and why he stopped the military activity. To what degree this was initiated by himself. He was extremely cautious. He received a closed Lenin prize around 1960."

${ }^{27}$ See IM's interview for VITA, israelmgelfand.com/talks/ vita.htm 1. In earlier years IM coauthored a series of works on neurophysiology based on grisly experiments on cats.

\section{${ }^{28}$ The trite lament that the cause of the sadness of today's world is that development of technology has overrun our moral development misses the point-for there is no moral develop- ment. Common decency now is the same as it was thousands of years ago, and it works well if applied (and if those who apply it are not killed). E.g., having taken it as religious principle (see https://en.wikepedia.ag/wiki/Jainism\#Doctrine), the Jains built a reasonable, i.e., nondestructive, society (maybe the only one still in existence). Their cousins in the West, the Good People (referred to as Cathars, "catlovers", by the adversaries), were eliminated in a feat of what now is called "globalization".}

29 "You should not explain to me that I am an idiot: I know this myself." Instructing Oleg Ogievetsky's mother on how to talk to physicians, IM asserted, "No one can revoke your inherent right to be a fool."

${ }^{30} \mathrm{~A}$ related fact is that in mathematics, unlike elsewhere, wrong notions die off easily. Our capacity for understanding is hampered, foremost, by the inability to dispel false concepts.

${ }^{31}$ See his Kyoto lecture, israelmgelfand.com/talks/kyoto. htm1, and a birthday party talk, www.math.harvard.edu/ conferences/unityofmath_2003/ta7ks/xgelfand-royalta1k.htm1. 